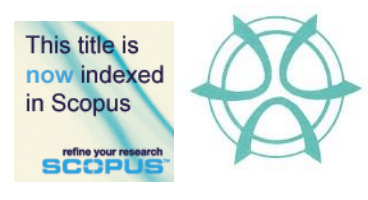

PLANNING MALAYSIA:

Journal of the Malaysian Institute of Planners

SPECIAL ISSUE V (2016), Page 49 - 64

\title{
ELDERLY AND COMMUNITY HEALTH CARE FACILITIES: A SPATIAL ANALYSIS
}

\author{
Rosilawati Zainol $^{1} \&$ Christopher J. Pettit $^{2}$ \\ ${ }^{I}$ Centre for Sustainable Urban Planning \& Real Estate \\ Faculty of Built Environment \\ UNIVERSITY OF MALAYA \\ ${ }^{2}$ Faculty of Built Environment \\ UNIVERSITY OF NEW SOUTH WALES
}

\begin{abstract}
The trend of ageing at home which is preferred option by the elderly in Australia is to be supported with good community facilities such as community health care facilities. The proximity of these facilities to their homes plays a significant role in their everyday life activity. Thus, this study examines the spatial relationship between elderly's population distribution and also the spatial distribution of community health care. Digital boundaries and population census 2011 data were retrieved from the Australian Bureau Statistics (ABS). Data on community health care facilities, on the other hand, were obtained from the National Health Services Directory (NHSD). Both data were analysed using Local Indicator Spatial Association technique (LISA). Results show there is a mismatch between the placement of community health care facilities and where the elderly reside. This mismatch will later create accessibility problems to the elderly if not tackle properly. They may be required to travel quite a distance to receive treatment and medications. Facilities are to be provided with projections of elderly population distribution in mind. This condition would minimize accessibility issue in the future.
\end{abstract}

Keyword: local indicator spatial association (LISA), spatial autocorrelation, ageing population, desire to age in place, spatial statistics 
Rosilawati Zainol \& Christopher J. Pettit

Elderly and Community Health Care Facilities: A Spatial Analysis

\section{INTRODUCTION}

Longer life expectancy and advancement in medical technology (Orimo et al., 2006) have led to the increasing number of elderly throughout the world, and the most can be seen in developed countries namely, the United States, European countries, Japan and Australia. Davies and James (2011) add a decrease in the rate of fertility and mortality also contributes to a longer life expectancy. There were 3 million people aged 65 and above in Australia according to the 2011 census (Australian Bureau of Statistics ABS, 2012). Australian aged population, 65 years and above has increased from $10.5 \%$ to $14 \%$ (2012). In its old elderly population, aged 85 years and above has also increased from $0.8 \%$ to $1.9 \%$ for the past 25 years (AIHW, 2012).

According to the recent census by the ABS, the ageing population prefers to stay at their home and remain active. Therefore, in encouraging an active and healthy ageing, the Australian Government is committed to ensuring that the aged population has access to a "high-quality, accessible and affordable care through a safe and secure aged care system". In responds to the increasing number of ageing population, about 7,933 residential care places and 1,724 community care places were allocated in December 2011 by the Aged Care Approval Round (ACAR) (DoHA, 2012). Community Care, funded by the Australian Government, provides home-based care to the older people and helps them to stay active and connected to their community. According to DoHA (2012) as of 30 June 2012, there were 46,518 Community Aged Care Packages (CACPs) provided to the frail aged people who prefer to live at home. While the government is trying its best to fulfil the needs, it is then worth examining the locations of the community care on whether its placement is within the ageing population catchment. Thus, this study intends to examine the spatial relationship between elderly's population distribution and also the spatial distribution of community health care. This condition is crucial since the services provided at these community health care centres such as pharmacy, health information and referral services, etc. are needed by the elderly.

\section{RESEARCH BACKGROUND}

This research background sections the context of the key variables which are to be analysed in the ensuing sections of this paper. These include (i) elderly population, (ii) community health care facilities and, (iii) proximity of health facilities.

\section{Elderly Population}

The elderly refers to a person aged 65 years old and above. According to the World Health Organization (WHO), this definition is widely acceptable by most of the developed countries. The increasing number of an ageing population requires the government to refine its public policies and economy. Sectors that 
are crucial to the elderly include housing, health, income security, residential services and economic opportunities (ABS, 2012).

According to the recent report issued by the Australian Institute of Health and Welfare (2013), many older Australians prefer to age in place. This notion is not a new concept as it has been discussed by previous scholars (Davies \& James, 2011; Rantz, Phillips, Aud, Popejoy, Marek, Hicks, Zailetti \& Miller, 2011; Beer, Smarr, Chen, Prakash, Mitzner, Kemp \& Rogers, 2012). By staying at their home, they can maintain independence, autonomy and connection for social support (Frank, 2002; Keeling, 1999). Furthermore, by staying at home, the cost of providing institutional care for the elderly can be avoided. Thus this move is favoured by not only the policymakers but also the elderly themselves (Davies \& James, 2011; WHO, 2007; Wiles, Leibing, Guberman, Reeve, \& Allen, 2012). As in Australia, there is about 75\% of those aged between 65-74 years old own their homes outright and about $82 \%$ of those aged 75 years old and above. These are the elderly who desire to age at their home. They claim that proximity to family, community and familiar services as the main reasons to do this (Davies $\&$ James, 2011). Thus, a healthy home environment should have a foundation for community care such as health services and care support (Davey, 2006; Lawler, 2001). However, according to Davies and James (2011), there is a decline in elderly's reliance on their children. They believe that the responsibility of taking care of them lies with themselves and the government. Thus, factors such as "affordability, amenity, type of housing, availability of formal care and supports networks" (Davies \& James, 2011:117) contribute to their preference to stay at home. Proximity and access to transportation network also influence the independent living. In the context of Australia, the study area for this research, the spatial distribution and proximity to services will be further analysed later in this paper. Figure 1 shows the location quotient of the elderly population. 


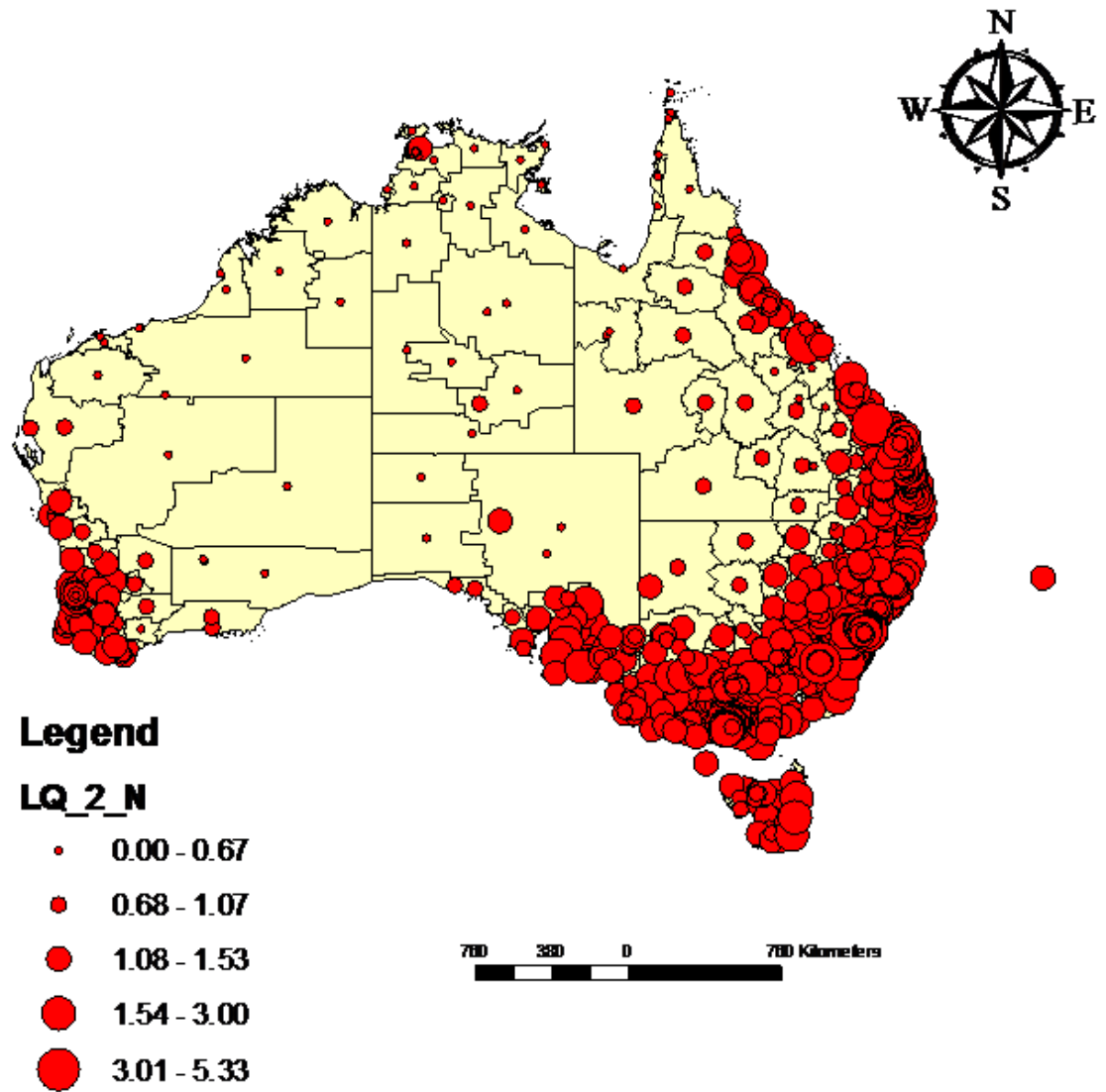

Figure 1: Location quotient for elderly population (Source: Study analysis, 2016)

\section{Community Health Care Facilities}

A significant body of research on community healthcare focuses more on the quality of services provided. This can be seen by works done by previous scholars; i.e. community health nurse home visit (Hosseini, Torkani \& Tavakol, 2013), role of community nursing in providing integrated care (Rao, 2014), community health workers (Witmer, Seifer, Finocchio, Leslie \& O'Neil, 1995), and, the importance of community health facilities (Adashi, Geiger \& Fine, 2010). In Australia, community health care refers to services that include health information and retrieval, pharmacy, maternal, child and family health, nurse-led clinics, women health clinic, food relief, veteran services, outreach service, social support, community cancer services, culturally tailored health promotion, family planning, immunization, Aboriginal health clinic, home medicine review, men's 
health clinic and walk-in facilities. Figure 2 shows the distribution of community health facilities in Australia.

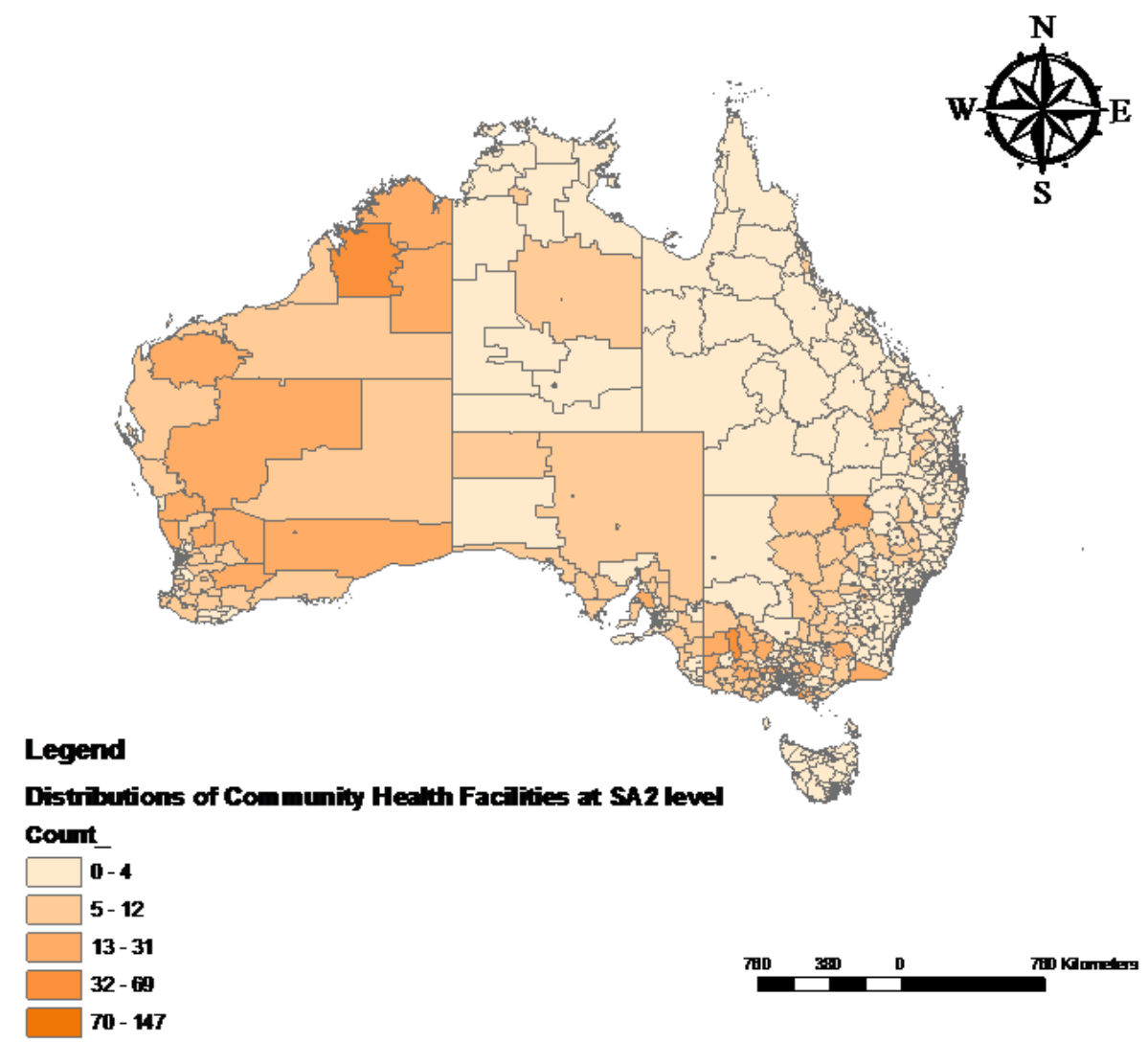

Figure 2: Distribution of community health facilities (Source: Study analysis, 2016)

\section{Proximity to Health Facilities}

According to Tobler's first law of geography, "everything is related to everything else, but near things are more related than distant things" (Tobler, 1970). Studies have shown that nearness is correlated to high utilization (Nemeta \& Bailey, 2000; Shannon, Bashshur \& Lovett, 1986). This finding is not new since Jarvis (1850) had conducted a systematic analysis of the association between distance and use of mental asylums in 1850. Before that Tuke (1814) cited in Shannon et al. (1986) had highlighted the problems of long-distance travelling and the establishment of asylum (Tuke, 1814). In another study, patients claimed that nearness is the reason for choosing health facilities (Fomba, Yang, Zhou, Liu \& Xiao, 2010). Thus, building a series of small hospitals is much better that building 
Rosilawati Zainol \& Christopher J. Pettit

Elderly and Community Health Care Facilities: A Spatial Analysis

a massive hospital and placed it in the central location (Jarvis, 1850). This situation will not only reduce the burden regarding cost but also reduce the disproportion uses of the hospitals by people from nearby and also from farther places (Jarvis, 1866). Moreover, a deprived neighbourhood can cause environmental stress to both vulnerable and non-vulnerable elderly (Van Der Meer, Fortuijn \& Thissen, 2008). However, the impact is more on the vulnerable ones. Thus, proximity to health facilities plays a significant role in determining healthy environment. This research will focus on the proximity of health care services in the context of Australia, where there is an increasing ageing population and demand for supporting facilities.

\section{METHODOLOGY}

This study employs a quantitative approach. All data are secondary data obtained from the Australian Bureau Statistics (ABS) and the National Health Services Directory (NHSD). ArcGIS software packages have been used to conduct the analyses.

\section{Source of Data}

Australian Government has come up with a new geographical framework called the Australian Statistical Geographic Standard (ASGS) which was effective since July 2011. It has been utilised in the 2011 Census of Population and Housing data release. There the 2011 census data are hierarchically organized through some nested geographies. Mesh blocks which contain about 347,627 units or blocks are the smallest geographical area defined by the ABS (Australian Bureau of Statistics ABS, 2013). In the Australian Statistical Geography Standard (ASGS) 2011 framework, SA1 is the second smallest statistical area level. It has an average population of 400. Its optimal population ranges between 200 and 800 people. The largest in ASGS would be SA4 which constitutes 106 regions with a population in the range of 100,000 to 500,000 (Australian Bureau of Statistics ABS, 2014).

Population data that contain data on the ageing population aged 65 and above according to statistical area level 2 (SA2) were obtained from the ABS website according to catalogue no. 3235.0. The data are updated until 30 June 2012 (Australian Bureau of Statistics, 2012). On the other hand, the data on community health care facilities that contain information on their specific locations were obtained from NHSD. Although the site of community health care is based on longitude and latitude, it still needs to be merged with digital geographical data that have at least statistical area level 2 (SA2) for further analysis. Thus, the statistical area level 2 (SA2) geographic data and also postcode data were obtained from ABS. Both data were merged. The procedures have been undertaken using the ArcGIS software package. Table 1 shows the list of community health care services according to categories. The distribution of 
PLANNING MALAYSIA

Sustainable Urban Development

these community health care facilities is quite dispersed throughout the country as will be described and analysed later in the paper.

Table 1: Number of community health care according to categories

\begin{tabular}{|c|c|c|c|}
\hline Community Health Care Category & Number & $\begin{array}{ll}\text { Community } & \text { Health } \\
\text { Care Category } & \\
\end{array}$ & Number \\
\hline Aboriginal health clinic & 231 & $\begin{array}{l}\text { Maternal, child and } \\
\text { family health }\end{array}$ & 1655 \\
\hline Community cancer services & 67 & Men's health clinic & 15 \\
\hline Culturally tailored health promotion & 49 & Nurse led clinics & 139 \\
\hline Family planning & 73 & Outreach service & 68 \\
\hline Food relief & 57 & Pharmacy & 5054 \\
\hline $\begin{array}{l}\text { Further description - community } \\
\text { health care }\end{array}$ & 660 & Social support & 362 \\
\hline Health advocacy/Liaison service & 288 & Veteran services & 26 \\
\hline Health information and retrieval & 1607 & Walk-in facilities & 45 \\
\hline Home medicine review & 14 & Women health clinic & 183 \\
\hline Immunization & 304 & & \\
\hline
\end{tabular}

\section{Method of Analysis}

Spatial autocorrelation has been used by various scholars to determine the relationship between locations of a single variable (Griffith, 1992; Douglas, Vogel \& Kroll, 2000; Berkelmans, De'ath, Kininmonth \& Skirving, 2004). This statement is related to Tobler's first law of geography which states that everything is connected to everything else but near things matter more (Griffith, 2009; Tobler, 1970). Moran's I is used to measuring this (Getis, 2007). Its analysis output can be classified as positive, negative and no spatial auto-correlation. But this is more of providing global indicators. Likewise, Local Indicator Spatial Association (LISA) allows for the decomposition of global indicators and provides results for each observation (Anselin, 1995). LISA is used in this study to examine the distribution of the community health care services and also the distribution of the elderly. These analyses show the relationship between a unit, in this case, the Statistical Area 2 (SA2) Level and its neighbouring unit (Anselin, 1995). It expands Moran's I capability and provides results in five categories; high-high cluster, low-low cluster, a high-low outlier, low-high outlier and not significant. High-high cluster refers to areas which have high values and are also surrounded by neighbouring areas that have high values too. They share some common attributes in a positive manner. Likewise, low-low cluster indicates the areas with low values and are surrounded by neighbouring areas which have low values. These two clusters show a significantly positive relationship between an area and its neighbours. Nevertheless, the outliers show a slightly different concept. It indicates the values that are highly significant but in a negative relationship. The high-low outliers present areas that have high values but are surrounded by neighbouring areas that have low values. On the other hand, the 
Rosilawati Zainol \& Christopher J. Pettit

Elderly and Community Health Care Facilities: A Spatial Analysis

low-high values imply that an area has low values but is surrounded by neighbouring areas which have high values. A unit might have high values, but its neighbouring unit might have low values and vice versa. In this study, LISA was carried out to observe the distribution of elderly and also the distribution of community health care.

LISA was carried out first with data on elderly aged 65 years and above and later on the community health care distribution. This technique determines the distribution of elderly's population and the distribution of community health care scientifically.

\section{FINDINGS AND DISCUSSION}

Results of LISA analysis show there are significant relationships between the distributions. First is the distribution of elderly aged 65 years old and above. The hotspots of age group are concentrated in the cities in the south-east part of the Australia namely Melbourne, Sydney, Adelaide and Brisbane. In Western Australia, only Dianella falls into a high-high cluster. There are about 510 SA2s that fall into this cluster category. This finding means these areas share a similar number of elderly residents. In addition, the majority of areas in Capital Territory, however, fall into a low-low cluster. Also, Northern Territory and most of Western Australia also have a low-low cluster.

The outliers are displayed as high-low and low-high clusters. The highlow cluster is found in 22 SA2s in the eastern part of Queensland and four SA2s in the western part Western Australia. The low-high outliers are mostly found in Capital Territory, Victoria, and most parts of New South Wales. These outliers show the significant negative relationship between the SA2 areas. This means the SA2s within these areas have a higher number of elderly, but they are surrounded by the areas with a low number of elderly. This is vice versa with the low-high cluster area. Table 2 shows the details. Figure 3 shows the output of LISA analysis on the distribution of elderly aged 65 years old and above.

Table 2: Total number of SA2s according to cluster category for distribution of elderly aged 65

\begin{tabular}{ll}
\hline Cluster Category & Number of SA2s (aged 65 and above) \\
\hline High-high cluster & 510 \\
Low-low cluster & 423 \\
High-low cluster & 26 \\
Low-high cluster & 276 \\
Not significant & 961 \\
\hline
\end{tabular}


PLANNING MALAYSIA

Sustainable Urban Development

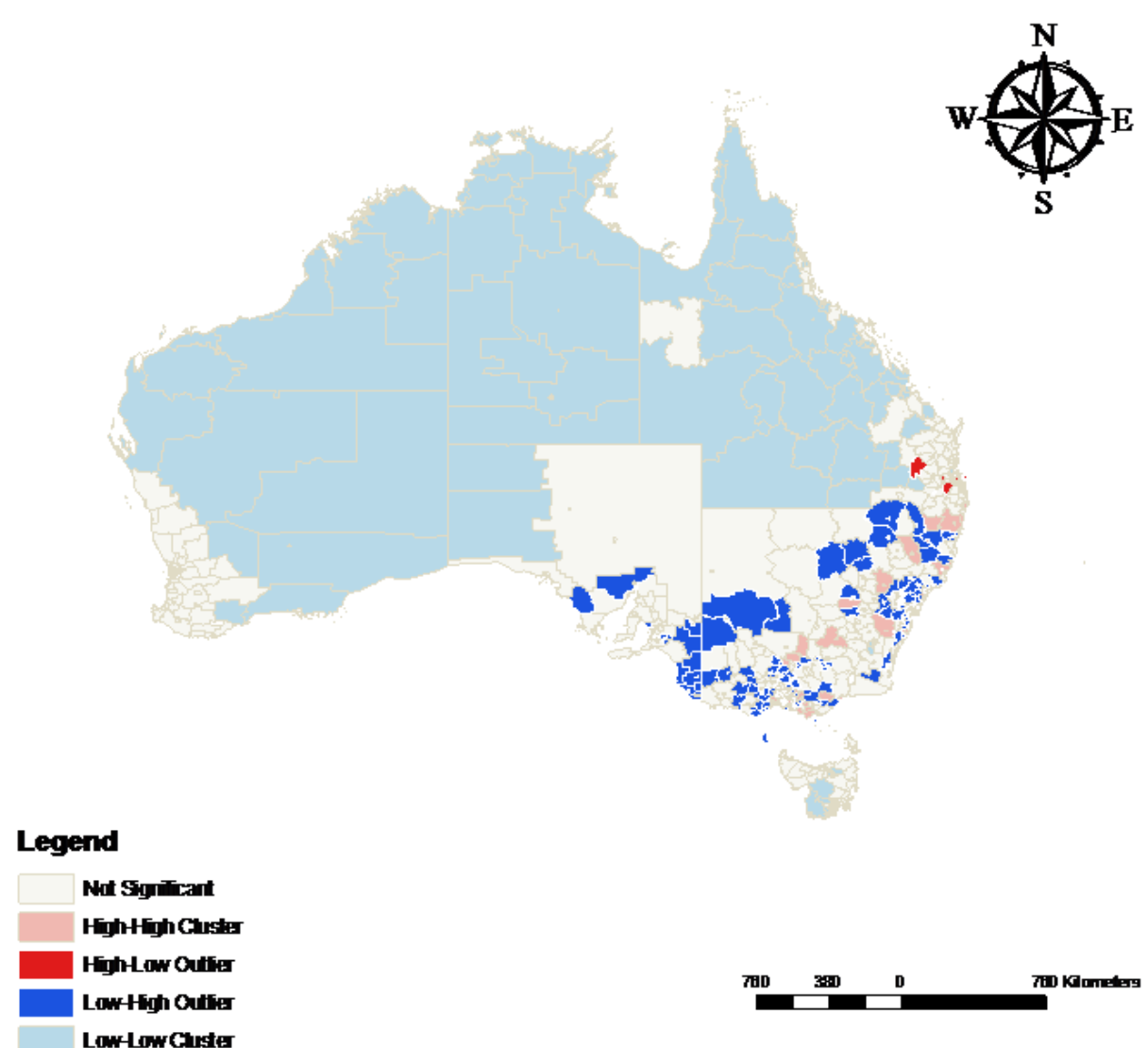

Figure 3: Results of LISA analysis on population distribution aged 65 and above Source: Study analysis, 2016

However, distribution of community health care reflects a different output. Most of the high-high cluster areas are mostly located in Western Australia (See Figure 4). Nevertheless, there are also found in southern part of South Australia, Victoria, Capital Territory and a small part of southwestern part of New South Wales. In addition, its low-low cluster is found in northern, eastern part of Queensland and north east of New South Wales. It has a bigger cluster for high-high than the low-low category (see Table 3). It's low-high covers the western part of New South Wales. It is also found in the north-western part of Western Australia. Nonetheless, the high-low cluster is located mostly in northeastern part of Australia and a few in the eastern part of the country. Regarding numbers, it has a higher number of high-high as compared to the others except for the not significant cluster. 
Rosilawati Zainol \& Christopher J. Pettit

Elderly and Community Health Care Facilities: A Spatial Analysis

Table 3: Total number of SA2s according to cluster category for distribution of community health care

\begin{tabular}{lc}
\hline Cluster Category & Number of SA2s \\
\hline High-high cluster & 2,476 \\
Low-low cluster & 739 \\
High-low cluster & 1,960 \\
Low-high cluster & 923 \\
Not significant & 48,674 \\
\hline
\end{tabular}

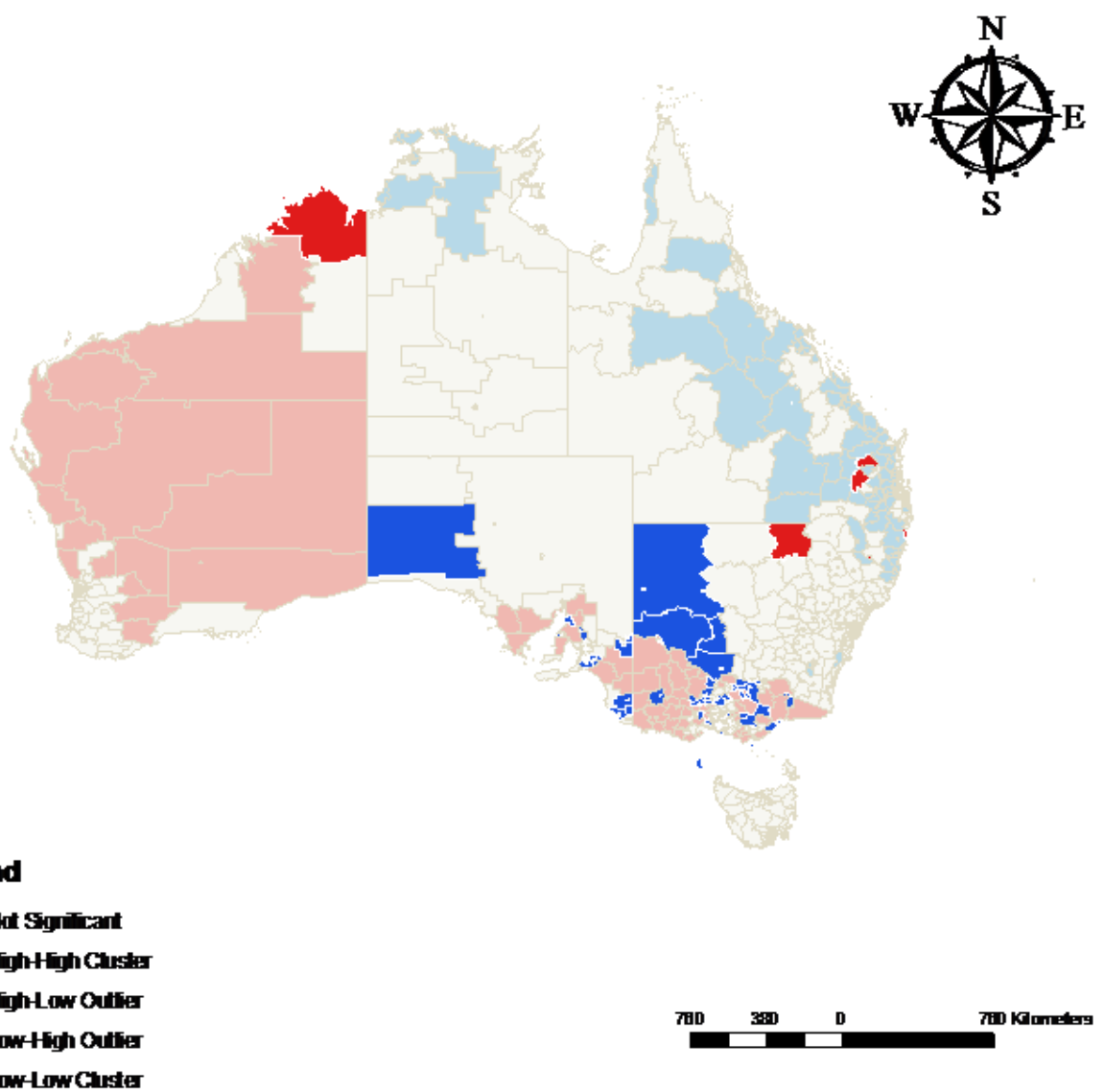

Figure 4: Results of LISA analysis on community health care distributions (Source: Study analysis, 2016) 
PLANNING MALAYSIA

Sustainable Urban Development

The results from LISA analysis show the distribution of community health care facilities does not match with the majority of the elderly's distribution. Most of the elderly are clustered in the south-eastern and southern part of Australia. These areas are the capital cities in Australia which include Sydney, Melbourne, Brisbane, and Adelaide. Historically, these cities are closely associated with the early settlements in Australia (Australian Government, 2016) that began in the early seventeen century. These cities are growing ever since, and concentration of elderly population are still at large in these cities (Australian Historical Population Statistics, 2016).

Whereas, the clustering of community health care facilities is more in areas with a low-low significant number of elderly which are in the northern and western part of Australia. The results indicate there is a mismatch in the location of community health care for elderly residents and where the elderly reside. Thus the notion of the ageing population who desire to age in place as claimed by (Davies \& James, 2011; WHO, 2007; Wiles et al., 2012) will not be realized if this condition persists. Furthermore, the findings of this study reveal that the current placements of community health care are obviously not by previous studies carried out by scholars such as Wiles (2005), Javis (1850) and Tuke (1814) who highlighted the importance of proximity in locating facilities to the people who need them.

The trend of elderly population in the next few decades would still be in the state of New South Wales, Victoria, Capital Territory, South Australia and also Queensland. Although the trend of elderly's population might be in these areas, however at the current situation, they need more of the community health care services now. The south-western part of Western Australia should also be observed. These are the SA2s that probably have a high or low number of elderly population, but they are neighbouring with areas that either have a low or a high number of elderly.

The current distribution of community health should be concentrated in the areas that a high number of elderly. Not only the elderly who wish to age in place due to various factors including high cost of staying in residential aged care facilities but also the politicians who would like to them to stay at home as long as possible to reduce the cost of building and maintaining the facilities. With the increasing number of elderly each year, proper budget needs to be allocated for their needs. According to the Australian Bureau of Statistics (2012: 2071.0), the number of elderly will escalate when the baby boomers enter the retirement age. This situation will be in a decade's time. Preparations to welcome the group have to be made earlier as to avoid other implications such as insufficient community health care facilities and inaccessible facilities. Thus, placement of the community health care facilities needs to be near their users to fulfill the elderly's needs. Furthermore, this will encourage high utilization of the said facilities as claimed by Nemeta \& Bailey (2000) and Shannon, et al. (1986). 
Rosilawati Zainol \& Christopher J. Pettit

Elderly and Community Health Care Facilities: A Spatial Analysis

This study has used LISA, specifically the Local Moran's I statistic in measuring the relationship of a single variable with individual locations. Understanding the spatial clusters of the population and support community facilities is important, and the use of such measure as the I Moran statistic can assist in in evidence-based planning and decision- s. Tobler's first law of geography is used as an underpinning principle in planning for community support facilities. This principle will not just ensure that the infrastructure provided is placed at the best location, but it will also be able to fulfill the needs of the society in improving the quality of life of those individuals wishing to utilise such facilities.

\section{CONCLUSION}

This study has not only determined the spatial correlation of elderly population and the distribution of the community health care facilities but also introduced another approach in planning decision making. The mismatch between the placement of community health care services and the locations where the elderly reside will result in poor accessibility to these facilities by the latter. The elderly may be required to travel quite a distance to receive treatment or obtain their medicines and other services. Problems will escalate when the number of elderly increases in areas where these facilities are not available. In addition, the desire to age in place further requires facilities to be located nearby. Thus, planners need to observe this situation regularly. Placement of facilities should be accessible to users especially the elderly since they may require assistance to reach these places.

This study only applies the LISA technique in analysing the data. Possibly, a bivariate Moran's I can be used to show the significant relationship between the distribution of elderly's population and the placement of community health care in a future study. Furthermore, it does not include projection data in the analysis. The next stage of the research will use demographic population projection data to analyse the expected change in the elderly population and the location of existing health care services systematically. 
PLANNING MALAYSIA

Sustainable Urban Development

\section{ACKNOWLEDGEMENTS}

The authors wish to thank the Australian Statistic Bureau and the National Health Services Directory for making their data available. This study was made possible through the Australian National Data Services (ANDS) Urban Health Connectivity project in collaboration with the Australian Urban Research Infrastructure Network.

\section{REFERENCES}

ABS, Australian Bureau of Satistics. (2013). 2011 Census Mesh Blocks. Retrieved 7 January, 2016, from http://www.abs.gov.au/ausstats/abs@.nsf/Latestproducts/ 1386.0Main\%20Features3602013?opendocument\&tabname=Summary\&pr odno $=1386.0 \&$ issue $=2013 \&$ num $=\&$ view $=$

ABS, Australian Bureau of Statistics. (2012). Who are Australia's older people? 2071.0 - Reflecting a nation: stories from the 2011 Census, 2012-2013. Retrieved 5 January, 2016

ABS, Australian Bureau of Statistics. (2014). Australian Statistical Geography Standard (ASGS). Retrieved 7 January, 2016, from http://www.abs.gov.au/websitedbs/

D3310114.nsf/home/Australian+Statistical+Geography+Standard+\%28AS GS\%29

Adashi, E. Y., Geiger, H. J. \& Fine, M. D. (2010). Health care reform and primary care - the growing importance of the community health center. New England Journal of Medicine, 362(22), 2047-2050. doi: doi:10.1056/NEJMp1003729

Anselin, L. (1995). Local Indicator of Spatial Association - LISA. Geographical Analysis, 27(2), 93-115.

Australian Government. (2015). European Discovery and the Colonisation of Australia. Retrieved 24 August 2016 from http://www.australia.gov.au/about-australia/australian-story/europeandiscovery-and-colonisation

Australian Historical Population Statistics, 2014 (cat. no. 3105.0.65.001) Australian Historical Population Statistics. Retrieved 24 August, 2016, from http://www.abs.gov.au/ausstats/abs@.nsf/mf/3105.0.65.001

Australian Historical Population Statistics, 2008 (cat. no. 2071.0) Reflecting a Nation: Stories from the 2011 Census, 2012-2013. Retrieved 7 March, 2016, from

http://www.abs.gov.au/ausstats/abs@.nsf/Lookup/2071.0main+features752 012-2013

Australian Bureau of Satistics, ABS. (2012). 3235.0 Population by age and sex, regions of Australia. Retrieved 6 January, 2016, from http://www.abs.gov.au/ 
Rosilawati Zainol \& Christopher J. Pettit

Elderly and Community Health Care Facilities: A Spatial Analysis

AUSSTATS/abs@.nsf/Lookup/3235.0Main+Features12012?OpenDocume nt

Australian Demographic Statistics (June 2012) (cat. no. 3101.0).

Australian Historical Population Statistics (2008) (cat. no. 3105.0.65.001).

Australian Institute of Health and Welfare (AIHW) (2012). Aged care packages in the community 2010-11: a statistical overview. Aged care statistics series no. 37. Cat. No. AGE 69. Canberra: AIHW.

Australian Institute of Health and Welfare (2013). The desire to age in place among older Australians. Bulletin no. 114. Cat. no. AUS 169. (1-20). Canberra: Australian Government.

Beer, J. M., Smarr, C.-A., Chen, T. L., Prakash, A., Mitzner, T. L., Kemp, C. C. \& Rogers, W. A. (2012). The domesticated robot: design guidelines for assisting older adults to age in place. Paper presented at the Seventh Annual ACM/IEEE International Conference on Human-Robot Interaction, Boston, Massachusetts, USA.

Berkelmans, R., De'ath, G., Kininmonth, S. \& Skirving, W. (2004). A comparison of the 1998 and 2002 coral bleaching events on the Great Barrier Reef: spatial correlation, patterns, and predictions. Coral Reefs, 23(1), 74-83. doi: $10.1007 / \mathrm{s} 00338-003-0353-\mathrm{y}$

Davey, J. (2006). Ageing in place: the views of older homeowners about housing maintenance, renovation and adaptation. Social Policy Journal of New Zealand 27, 128-141.

Davies, A. \& James, A. (2011). Goegraphies of Ageing, Social Processes and the Spatial Unevenness of Population Ageing. Surrey, England: Ashgate.

DoHA, Department of Health and Ageing (2012). 2010-11 Report on the Operation of the Aged Care Act 1997. Canberra: DoHA.

Douglas, E. M., Vogel, R. M. \& Kroll, C. N. (2000). Trends in floods and low flows in the United States: impact of spatial correlation. Journal of Hydrology, 240(1-2), 90-105. doi: http://dx.doi.org/10.1016/S0022-1694(00)00336-X

Fomba, S., Yang, Y., Zhou, H., Liu, Q. \& Xiao, P. M. (2010). Patient's utilization and perception of the quality of curative care in community health centers of the Fifth Commune of Bsamako. Indian Journal of Community Medicine : Official Publication of Indian Association of Preventive \& Social Medicine, 35(2), 256-261. doi: 10.4103/0970-0218.66882

Frank, J. B. (2002). The Paradox of Aging in Place in Assisted Living. London: Bergin \& Garvey.

Getis, A. (2007). Reflections on spatial autocorrelation. Regional Science and Urban Economics, 37(4), 491-496. doi: http://dx.doi.org/10.1016/j.regsciurbeco. 2007.04.005

Griffith, D. A. (1992). What is spatial autocorrelation? Reflections on the past 25 years of spatial statistics. I'Espace Geographique, 21, 265-280.

Griffith, D. A. (2009). Spatial Autocorrelation. 1-10. http://booksite.elsevier.com/ brochures/hugy/SampleContent/Spatial-Autocorrelation.pdf 
Hosseini, H., Torkani, S. \& Tavakol, K. (2013). The effect of community health nurse home visit on self-care self-efficacy of the elderly living in selected Falavarjan villages in Iran in 2010. Iranian Journal of Nursing and Midwifery Research, 18(1), 47-53.

Jarvis, E. (1850). The influence of distance from and proximity to an insane hospital, on its use by any people. The Boston Medical and Surgical Journal, 42(11), 209-222. doi: doi:10.1056/NEJM185004170421101

Jarvis, E. (1866). Influence of distance from and nearness to an insane hospital on its use by the people. American Journal of Insanity, 22, 361-418.

Keeling, S. (1999). Ageing in (a New Zealand) place: ethnography, policy and practice. Social Policy Journal of New Zealand, 13, 95-114.

Lawler, K. (2001). Aging in Place: Coordinating Housing and Health Care Provision for America's Growing Elderly Population. Washington, DC: Joint Center for Housing Studies of Harvard University \& Neighbourhood Reinvestment Corporation.

Nemeta, G. F. \& Bailey, A. J. (2000). Distance and health care utilization among the rural elderly. Social Science \& Medicine, 50(9), 1197-1208.

Orimo, H., Ito, H., Suzuki, T., Araki, A., Hosoi, T. \& Sawabe, M. (2006). Reviewing the definition of "elderly". Geriatrics \& Gerontology International, 6(3), 149-158.

Rantz, M. J., Phillips, L., Aud, M., Popejoy, L., Marek, K. D., Hicks, L. L., . . Miller, S. J. (2011). Evaluation of aging in place model with home care services and registered nurse care coordination in senior housing. Nursing Outlook, 59(1), 37-46. doi: http://dx.doi.org/10.1016/j.outlook.2010.08.004

Rao, T. (2014). The role of community nursing in providing integrated care for older people with alcohol misuse. Br J Community Nurs, 19(2), 80, 82-84.

Shannon, G. W., Bashshur, R. L. \& Lovett, J. E. (1986). Distance and the use of mental health services. The Milbank Quarterly, 64(2), 302-330. doi: $10.2307 / 3349974$.

Tobler, W. R. (1970). A computer model simulation of urban growth in the Detroit region. Economic Geography, 46, 234 - 240.

Tuke, S. (1814). Description of the Retreat: an Institution for Insane Persons of the Society of Friends. Philadelphia: Pierce.

Van Der Meer, M., Fortuijn, J. D. \& Thissen, F. (2008). Vulnerability and environmental stress of older adults in deprived neighbourhoods in the Netherlands. Tijdschrift voor Economische en Sociale Geografie, 99(1), 5364.

WHO, World Health Organization. (2007). Global Age-Friendly Cities: A Guide. Geneva: World Health Organization.

Wiles, J. L., Leibing, A., Guberman, N., Reeve, J. \& Allen, R. E. S. (2012). The meaning of "aging in place" to older people. The Gerontologist, 52(3), 357366. doi: 10.1093/geront/gnr098 
Rosilawati Zainol \& Christopher J. Pettit

Elderly and Community Health Care Facilities: A Spatial Analysis

Wiles, J. (2003). Daily geographies of caregivers: mobility, routine, scale. Social Science \& Medicine, 57(7), 1307-1325. doi: http://dx.doi.org/10.1016/S0277-9536(02)00508-7

Wiles, J. (2005). Conceptualizing place in the care of older people: the contributions ofgeographical gerontology. Journal of Clinical Nursing, 14(8b), 100-108.

Witmer, A., Seifer, S. D., Finocchio, L., Leslie, J. \& O'Neil, E. H. (1995). Community health workers: integral members of the health care work force. American Journal of Public Health, 85(8_Pt_1), 1055-1058. doi: 10.2105/AJPH.85.8_Pt_1.1055

World Health Organization. (2015). Health statistics and information systems. Retrieved 29 December, 2015, from http://www.who.int/healthinfo/ survey/ageingdefnolder/en/\# 